\title{
Research on the Logic and Thinking of Constructing Fault Tolerant Mechanism under Pressure Management in China
}

\author{
Qin Guo ${ }^{1, a}$ \\ ${ }^{1}$ School of Public Administration, Sichuan University, Chengdu, Sichuan, 610064 \\ ${ }^{a}$ email
}

Keywords: Pressure - based Governance, Fault -Tolerant Mechanism, Mechanism Construction

\begin{abstract}
Chinese great achievements in economic construction due to the Chinese characteristics of the pressure-based governance model at a large extent. Under the pressure management, the policy indicators together with the responsibility and pressure by layer decomposition overweight, and it is seen as an important basis for cadre assessment. A small number of cadres avoid mistakes in the work and not dare and do not want to make mistakes. The construction of scientific and reasonable fault-tolerant mechanism is not only a return to the "limited rationality" of the cadres, but also an effective complement to the defects of the pressure-type governance, which provides a system guarantee for comprehensively deepening reform.
\end{abstract}

\section{Introduction}

China is the implementation of the target responsibility system and the next level of responsibility system as the core of the pressure-based governance model. In the pressure of governance, the higher-level leadership sector one-sided pursuit of economic development indicators, the indicators were layers of overweight, the pressure was gradually enlarged, a small number of cadres to avoid mistakes were eliminated, dare not play, do not want to take the initiative, Gradually formed in the official field of lazy indignation of the bad atmosphere, not only affected the implementation of the policy, but also a comprehensive deepening reform and institutional mechanisms for the important obstacles to innovation. The timely presentation of fault-tolerant mechanisms and scientific construction will help to solve this problem.

\section{The Connotation and Characteristics of Stress Management}

In the Chinese political system, the local government in order to achieve economic catch-up, speed up the local social and economic development, the completion of the higher orders and indicators issued by the set of administrative orders and material incentives combined with the governance model the pressure-based governance mainly depends on the order, management and control methods such as governance. In the specific form, the pressure system through the target responsibility system, leadership responsibility system and the "one vote veto" system to be embodied and it has become the basic systems of pressure system. Target responsibility is for the core of pressure-based governance, the higher authorities to develop policy objectives from top to bottom layer by layer decomposition, the formation of a more comprehensive indicators and assessment system. In this set of economic development as the core indicator system, driven by government departments at all levels to compete for scarce administrative resources and fierce competition, not only caused the function of cross and waste of resources, but also led to corruption and power rent-seeking behavior.

The governance of stress is based on the theory of public choice. Cadres are regarded as "economic people". Their motives are mainly derived from economic incentives, and their efforts are to pursue their own interests and maximize their personal power. Government departments not only need to set clear objectives for the officials, but also to establish a set of effective power control and accountability system, through pressure transmission to promote their full competition in the conditions to complete the task indicators. The governance of stress has a better impetus in improving administrative efficiency and fulfilling goal responsibility. However, due to too much 
emphasis on instrumental rationality, it neglected the need for cadres' social development and self-realization, and the effective response to the public's overall demands, Fairness, justice, integrity, integrity and other public values.

Pressure management responds to the "rational person" hypothesis, that the cadres in the decision-making to collect and deal with all the relevant information, and listed in the policy options to balance the pros and cons after making the optimal decision. Pressure management in the system design does not objectively recognize the possibility of official decision-making mistakes, the lack of appropriate fault-tolerant space and the cadres once the decision-making mistakes will be severely punished, and all work efforts have been completely negative. "Only promised not to fail" is the proper interpretation of the pressure-based governance logic. Cadres gradually formed a system of pressure-dependent governance, values and business outlook also will change, "more dry and more wrong, less wrong, quit good" to become part of the work of the cadres of the creed. In the context of the current comprehensive and strict administration of the party and the strengthening of cadres' accountability, some cadres have not dared to act because of fear and mistakes. They have not been able to do so. They are not only likely to cause the outlay of the active cadres, but also seriously undermine the administration Ecological, affecting the "four comprehensive" strategic layout of the effective advance.

\section{The Pressure Management under the Construction of Fault-Tolerant Mechanism}

Premier Li Keqiang in the 2016 "government work report" proposed "to establish a sound fault-tolerant error correction mechanism" for the first time this is the computer industry terminology "fault tolerance" once applied to the management field. The meaning of fault-tolerant mechanism is that in the process of innovation and development, the errors and deviations in the exploratory practice of tolerance reformers are corrected by the corresponding mechanism, and the corresponding responsible person is exempted from the healthy development of the cause.

In the current situation of pressure to promote development, wind and anti-corruption and accountability continue to increase the situation, the central timely put forward the establishment of fault-tolerant mechanism, to crack down on lazy slaves, to stimulate the enthusiasm of cadres and entrepreneurs have an important role.

First, the fault-tolerant mechanism can compensate for the drawbacks of stress-based governance. The long - term existence and development of pressure - type governance in China has its rationality and inevitability. Pressure governance is a kind of expeditious social control mechanism that the state should respond to the gradual failure of the traditional social control mechanism in the market reform. In Chinese current economic growth slowdown, accelerated economic restructuring and social contradictions in the situation, to pressure governance to promote the deepening of the deepening of reform is a long period of time for a long period of national development of rational choice. Although the theory of network governance has a positive effect on Chinese governance theory and practice, it is mainly manifested in the field of social governance and has little effect on the operation and governance of the government itself. Chinese long-term pressure-based governance in the cadre style, political ecology and official culture has had a negative impact, directly to the performance of some cadres in the lack of work and innovation and entrepreneurial power. The construction of fault-tolerant mechanism is in the current government governance power control and incentive mechanism is not yet mature stereotypes, the relevant supporting system has not yet keep up with the situation, for the courage to reform and innovation of the cadres of a certain "trial and error space" and " Space "is not only respect for the law of reform and innovation, but also on the pressure of governance breakthroughs and innovation, to a certain extent make up for the pressure of governance system defects.

Second, the fault-tolerant mechanism can make the cadres return to bounded rationality. Cadres and then the ability and experience is not God, people in the process of decision-making there must be the possibility of making mistakes. Pressure-type governance argues that it is only a theoretical assumption that cadres can collect and process all information in decision-making and list all options to make optimal decisions. There is a lack of feasibility and necessity in reality. Herbert 
Simon's decision-making theory argues that the manager of reality is "boundless rationality" between "perfect reason" and "irrationality". Managers do not have a long-term, stable, and mature value preference system because of their own knowledge, ability, experience and limited information. They can not find all the alternatives in practice and can not predict the alternatives. It can be seen that the zero tolerance of pressure-based governance on decision-making risks and "one-vote veto" is an irrational attitude. Various non-deterministic factors in the process of reform and innovation can lead to the decision-making mistakes of cadres and become the victims of the reform. The fault-tolerant mechanism is based on the theoretical hypothesis of "bounded rationality". It is the reconstruction and re-cognition of the rationality of the cadres' values. The actual recognition of the possibility of the cadres in the decision-making because of the lack of experience and the possibility of fault tolerance and trial and error Space, effectively protect the enthusiasm and initiative of reformers, reflecting the organizational departments of the "willing to do things, dare to do things, capable of" cadres of the care.

The fault-tolerant mechanism can provide a system guarantee for the comprehensive deepening of reform. Deepening the reform is a fundamental way to solve the problem of reality, is to determine China to achieve "two hundred years" goal of a key move. Chinese reform mainly to take the "stone across the river," the progressive strategy is to try to try the process of reform and experience and the law. At present, Chinese reform has entered the deep water area and the crucial period, the interest groups are more and more, the resistance encountered is also growing, to promote the complexity of the reform, the sensitivity level is no less than the early reform and opening up. Cadres in the reform not only to face the risk of decision-making, but also bear the policy risk, economic risk and public opinion risk. In the face of various deep-seated contradictions and the risk of reform, these "hard bones", some cadres fear of fear, looking forward, neglect and sluggishness and other phenomena have risen, and some places even appeared "reform idle" phenomenon. Under the circumstance of deepening the lack of reform power, we will build a scientific and reasonable fault-tolerant mechanism, actively create an atmosphere of encouraging reform and tolerance failure, and can effectively solve the problem of reforming the "last mile" so that cadres can solve their worries and maximize the enthusiasm of cadres Enthusiasm for the comprehensive deepening of reform to provide long-term strong system of protection.

\section{The Scientific Construction of Fault-Tolerant Mechanism of Thinking}

The construction of fault-tolerant mechanism is itself a new thing in reform, it is necessary to do the top-level design, but also in the practice of exploration to improve the corresponding supporting system to ensure that the fault tolerance mechanism of the direction, scientific and operational.

First, the fault tolerance mechanism needs to define the scope of application. Fault tolerance mechanism is not applicable to all the mistakes of cadres, but should not be a small number of cadres to avoid the party discipline and state sanctions "umbrella" and "file Wrigley". Fault tolerance mechanism is actually an incentive mechanism and the key premise is to establish a strict use of standards and scope of application. General Secretary Xi Jinping repeatedly mentioned in the 18th after the "three to distinguish", in fact, for the scientific screening errors, delineation of the scope of the proposed guiding principles. Usually from the point of view of mistakes, can be divided into objective errors and subjective errors; from the perspective of behavior can be divided into exploratory errors and banned more than the error; from the utilitarian point of view, can be divided into public welfare errors and abuse ; From the point of view of decision-making process, can be divided into collective errors and personal errors; from the perspective of decision-making results can be divided into errors and omissions as errors. For the cadres in the reform and innovation in the mistakes committed, not only to distinguish between the wrong nature and type, but also the wrong and the wrong people to distinguish. To take the initiative to play, as positive, dare to try wrong, bold and innovative cadres, the organization departments to protect and training, knowingly guilty, desperate, loss of public welfare, especially in the eighteen after the convergence of cadres should be resolutely dealt with. It is necessary to establish a "list of powers", "list of responsibilities" and "fault-tolerant list" at the same time, so that "encourage and support what" and 
"oppose the prohibition of what" is clear, Deepen the reform of organic unity, for the cadres to create a serious tension without losing open lively business environment.

Second, the fault-tolerant mechanism should be coordinated with the error correction mechanism. From the "2016 government work report" proposed in the "establish a sound fault-tolerant error correction mechanism" can be seen, fault-tolerant mechanism and error correction mechanism from the outset is a holistic concept, if put aside the error correction mechanism and talk about fault-tolerant mechanism, Not only deviated from the central intention of establishing a fault-tolerant mechanism, but also weakened the value and significance of its existence. Fault-tolerant mechanism is not for the cadres of the wrong short, but in the wrong time to stop in time to do the education and correction of cadres to prevent further deepening the negative, further negative impact, so that reform and innovation to return to the right direction. Therefore, the fault-tolerant mechanism and error correction mechanism must be established at the same time, and the formation of the corresponding supporting system. After the cadres have made mistakes, the organization and discipline supervision departments should conduct investigations in accordance with the corresponding procedures and be able to avoid the accountability of the errors in the scope of the fault-tolerant mechanism. They should handle the results in a timely manner and talk with the cadres at the same time to help him to remove the ideological burden, Sum up lessons, correct relevant errors, and reintroduce ideas and actions into business.

Third, the fault-tolerant mechanism should be used in conjunction with the incentive mechanism. Fault-tolerant mechanism is conducive to helping cadres in the process of reform and innovation to remove the burden and pressure of thought, but can not fundamentally solve the problem of innovation and innovation of cadres' reform. Fault-tolerant mechanism is more like a "two-factor theory" in the health factors, rather than incentives and it can only be used in conjunction with other rewards and punishments can play a stimulating effect. Therefore, we should change the evaluation mechanism of cadre examination, strengthen the weight of reform and innovation indicators, play the role of evaluation mechanism in the selection and employment of people, so that the masses, non-profit organizations, the private sector and social media are also involved in the reform of cadres and innovation performance evaluation of. In the selection mechanism of the cadres, improve the "good cadres to use up" the cadre selection mechanism, breaking the "seniority, balanced care" of the unspoken rules, evaluation of cadre performance and ability can not only focus on economic development indicators, but also depends on social development, Protection and innovation and development of comprehensive indicators, so as to let the officers have the opportunity to have a stage of the Secretary, do the status of success. Do not have to complete the standard to choose people to use, to reform and innovation in the courage to play, to achieve significant results of the cadres to give spiritual and material incentives; mistakes or mistakes in the cadres, in a timely manner to enable fault-tolerant mechanism, but also consider the post adjustment, level of communication, etc., to give them a chance to re-prove their own and the stage.

\section{The Problem Needs Attention of the Construction of Fault-Tolerant Mechanisms}

First, the correct handling of fault-tolerant mechanisms and party members accountability. Party accountability and fault-tolerant mechanisms are the last two periods of the same time the emergence of two theoretical hot words, to clarify the relationship between the two, for the construction of fault-tolerant mechanism is of great significance. First, the fault-handling mechanism and the accountability logic are different. Accountability is the embodiment of stress governance in the field of strict governance, is to strengthen the supervision of cadres under the logic of the inevitable product. The fault-tolerant mechanism is in the process of governance transformation, in the maintenance of the effectiveness of pressure-based governance and authority on the basis of theoretical breakthroughs and institutional innovation. Second, the purpose of the two is different. The fault-tolerant mechanism is to reduce the pressure of party and government cadres in reform and innovation, to stimulate the enthusiasm of their officers and entrepreneurship, to support reformers, so as to promote the deepening of the deepening of reform. The Cadre Accountability Ordinance is a manifestation of the requirements of a comprehensive and strict rule 
of the party, the implementation of party organizations to manage party responsibility, and urge the party cadres to be honest and courageous. Again, the relevance of the two, the fault-tolerant mechanism for the behavior of reform and innovation in the emergence of errors and deviations, these errors are due to first try, lack of experience or no intention of negligence caused. The six accountability situations stipulated in the accountability ordinance mainly include the weakening of the party's leadership, the lack of party building, the strict management of the party, the maintenance of the party's discipline, the promotion of party integrity and anti- Firm and other dereliction of duty, and the scope of application of fault tolerance mechanism is not contrary to the scope of fault tolerance mechanism from the severity and influence are not the "Regulations" of the punishment situation. Finally, the punishment of the two different ways, "Ordinance" accountability for the party organizations and individuals are divided into two categories. The accountability of the party organization mainly includes inspection, notification, reorganization and personal accountability, including notification, admonition, organization of investigation or organization, disciplinary action. The fault-tolerant mechanism is in the scientific recognition of the exemption and the essence is an incentive mechanism.

The second is to prevent fault-tolerant mechanisms in the process of institutional conflict and asylum-like corruption. In recent years, from the 18th Party Congress put forward "to establish a sound decision-making accountability and error correction system" to the Fourth Plenary Session of the Eighteenth National Congress put forward "to establish a major decision-making responsibility for accountability and accountability mechanism", and the newly issued Regulations on Disciplinary Punishment of the Communist Party of China, the Regulations of the Communist Party of China on Integrity and Self-discipline, the Regulations on the Accountability of the Communist Party of China, and so on, all of which show that Chinese current policy accountability and cadre supervision of the high pressure situation, not only the system is more perfect, the implementation of efforts are greatly enhanced. Significant decision-making lifelong accountability and accountability review system as an important measure to strengthen cadre decision-making is also gradually deepening the implementation. In the specific implementation process, the fault-tolerant mechanism may be inconsistent with the major decision-making mistakes, leading to the decision should not be allowed to make mistakes, the responsibility of the decision-making mistakes have not been pursued. In addition, the fault-tolerant mechanism is designed to protect and motivate the enthusiasm of the cadres. Objectively requires that the mistakes made by the cadres within the scope of the fault-tolerant mechanism should not be pursued, but the same principal behavior can not be applied to the system and the system resulting in fault between the fault-tolerant mechanism and the decision-making system

\section{References}

[1] [3] Zeng Fanjun: holistic governance: a pressure governance of the transcendence and substitution model [J]. Jianghan Forum, 2013 (12): 21-22.

[2] Rong Jing Ben: from the pressure system to the democratic cooperation system changes - county and township levels of political reform, the Central Compilation and Translation [M]. 1997: 55

[4] Liu Ninging et al: how to construct the fault-tolerant mechanism under the new normal state [J]. People's Forum, 2016 (4): 18-20.

[5] He Xianming: the process of market-oriented local government behavior logic, People's Publishing House [M]. 2008: 12

[6] Herbert Simon: Management Behavior, Machinery Industry Press [M]. 2013.

[7] Jiang used to: a reasonable spirit to create a fault-tolerant mechanism [J]. People's Forum, 2016 (4): 11-14.

[8] Mei Lirun. A comprehensive deepening of the reform situation "fault-tolerant mechanism"[J]. Chongqing Social Sciences, 2016 (6) 